\title{
UNIQUE
}

THE FIRST SURVEY OF THE REMARKABLE BREADTH OF DR. THOMAS L. SAATY'S WORKS

\section{Mujgan Sağır}

E-mail: mujgan.sagir@gmail.com

\begin{abstract}
This paper presents a draft of first literature survey for Dr. Thomas L. Saaty's works. Its purpose is to show the already known fact that how "unique" Dr. Saaty was for not only his hundreds of academic works, papers, books, seminars, students but also for his extraordinary personality by pointing out some of his researches related to the social issues together with humanity and world peace. We hope that this review will be a guide and inspiration for other researchers. This survey is the first one but will not be the last one because his methods continuously will be using in the future.
\end{abstract}

Key words: Literature review. 